\title{
KEPUASAN PELANGGAN TERHADAP PELAYANAN PT INTERYASA DUMAI MENGGUNAKAN METODE SERVICE QUALITY (SERVQUAL) DAN QUALITY FUNCTION DEPLOYMENT (QFD)
}

\author{
Soni Fajar Mahmud \\ Program Studi Teknik Industri, Sekolah Tinggi Teknologi Dumai \\ Jl. Utama Karya Bukit Batrem II \\ e-mail:sfajarmahmud@gmail.com
}

\begin{abstract}
ABSTRAK
Dalam bisnis jasa, perusahaan harus dapat memberikan pelayanan sesuai dengan apa yang diharapkan pelanggan. Penelitian ini dilakukan di Dumai dengan membuat kuesioner dengan menggunakan variabel Service quality (Servqual) dan Quality Funcion Deployment ( $Q F D$, dimana didalam variabel Servqual terdapat 5 dimensi, yaitu: Tangibles, Reliability, Responsivness, Assurance dan Empathy. Dari analisis terhadap 55 sampel diperoleh data yang menunjukkan bahwa pelanggan merasa tidak puas terhadap pelayanan PT.Interyasa Dumai Untuk meningkatkan kualitas layanan PT.Interyasa Dumai harus melakukan perbaikan terhadap kinerjanya, serta perusahaan juga harus konsisten dalam melakukan pelayanan pada konsumen.
\end{abstract}

Kata Kunci: Kepuasan pelanggan, Servqual, $Q F D$

\begin{abstract}
In the service business, the company must be able to provide services in accordance with what is expected customers. This research was conducted in Dumai by making a questionnaire using Service Quality (Servqual) and Quality Funcion Deployment (QFD), which in Servqual variable there are 5 dimensions, namely: Tangibles, Reliability, Responsiveness, Assurance and Empathy. From the analysis of 55 samples obtained data which indicates that the customer is not satisfied with PT.Interyasa Dumai service. To improve the quality of PT.Interyasa Dumai service must make improvements to its performance, and the company must also be consistent in performing services to consumers.
\end{abstract}

Keywords: Customer satisfaction, Servqual, QFD

UNITEK. Vol. 10 No. 2 Juli - Desember 2017 | p-ISSN 2089-3957 | e-ISSN 2580-2585 


\section{Pendahuluan}

Persaingan yang ketat antar perusahaan timbul karena semakin selektifnya konsumen dalam memilih dan menggunakan produk atau jasa. Situasi ini memacu setiap perusahaan untuk menghasilkan kualitas produk atau jasa yang lebih baik sesuai dengan harapan pemakainya, sehingga kepuasan dari pelanggan dapat terpenuhi. Untuk dapat memenangkan persaingan dalam dunia bisnis, hal utama yang harus diperhatikan oleh perusahaan adalah kepuasan pelanggan (customer satisfaction).

Setiap perusahaan harus mampu menyediakan produk sesuai kebutuhan dan keinginan pelanggan. Begitu pula dalam bisnis jasa perusahaan harus dapat memberikan pelayanan sesuai dengan apa yang diharapkan pelanggan, sehingga kualitas sesuatu yang harus diputuskan oleh pelanggan. Oleh karena itu, dirasa perlu untuk melakukan penelitian tentang kepuasan pelanggan terhadap pelayanan PT Interyasa Dumai menggunakan metode Service Quality (Servqual) dan Quality Function Deployment (Qfd)

\section{Metode Penelitian}

Pada penelitian ini, metode pengukuran kepuasan pelanggan yang digunakan adalah metode servqual yang meliputi lima dimensi kualitas jasa yaitu; Tangibles, Reliability, Responsiveness, Assurance, dan Empathy. Berikut penjelasan mengenai ke-5 dimensi di atas, yaitu:

1. Tangibles (bukti langsung), menggambarkan fasilitas fisik, perlengkapan, dan tampilan dari personalia serta kehadiran para pengguna.

2. Reliability (keandalan), merujuk kepada kemampuan untuk memberikan pelayanan yang dijanjikan secara akurat dan handal.

3. Responsiveness (daya tanggap), yaitu kesediaan untuk membantu pelanggan serta memberikan perhatian yang tepat.

4. Assurance (jaminan), merupakan karyawan yang sopan dan berpengetahuan luas yang memberikan rasa percaya serta keyakinan.

5. Empathy (empati), mencakup kepedulian serta perhatian individual kepada para pengguna.

\section{House of Quality (HoQ)}

Proses QFD meliputi penyusunan satu atau lebih matriks. Matriks yang pertama disebut rumah mutu (House of Quality), yang merupakan matriks perencanaan dan pengembangan produk atau jasa. HOQ menunjukkan keinginan konsumen (suara dari konsumen) yang terletak di 
sebelah kiri dan respon teknis dari tim pengembangan untuk menemui keinginan yang berada sepanjang atas matriks.

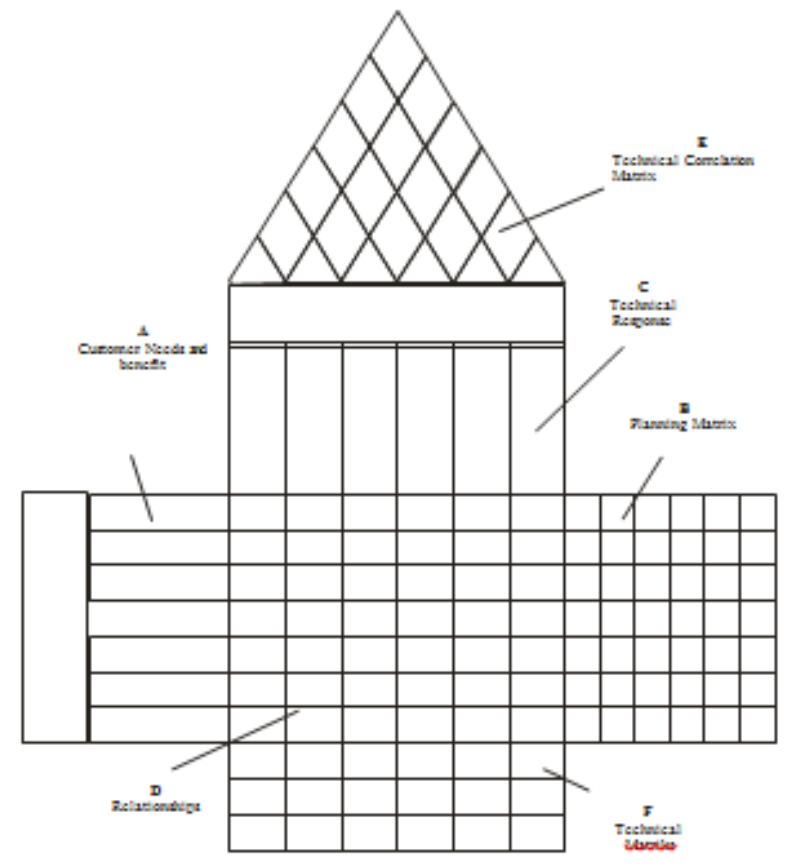

Keterangan:

a. Bagian A: Customer Needs and Benefits

b. Bagian B: Planning Matriks

c. Bagian C: Technical Responses

d. Bagian D: Relationship

e. Bagian E: Technical Correlation

f. Bagian F: Technical Matriks

\section{Gambar 3. House of Quality}

\section{Manfaat Quality Function Deployment}

Adapun manfaat dari Quality Function Deployment (Ariani, 2009) antara lain sebagai berilut:

a. Mengurangi Biaya

Hal ini dapat terjadi karena produk yang dihasilkan benar-benar sesuai dengan kebutuhan dan harapan pelanggan, sehingga tidak ada pengulangan pekerjaan atau pembuangan bahan baku karena tidak sesuai dengan spesifikasi yang telah ditetapkan oleh pelanggan.

b. Meningkatkan pendapatan

Dengan mengurangi biaya, maka hasil yang kita terima akan lebih meningkat.

c. Pengurangan waktu produksi 
QFD adalah kunci penting dalam pengurangan biaya produksi. QFD akan membuat tim pengembangan produk atau jasa untuk membuat keputusan awal dalam proses pengembangan.

Selain manfaat tersebut di atas, manfaat lain dari Quality Function Deployment (Purnomo, 2005) adalah:

a. Fokus pada pelanggan

QFD memerlukan masukan dan umpan balik dari pelanggan. Informasi berupa masukan dan umpan balik tersebut merupakan persyaratan pelanggan yang spesifik.

b. Efisiensi waktu

Dengan teridentifikasi persyaratan-persyaratan pelanggan QFD dapat mengurangi waktu dalam pengembangan produk.

c. Berusaha teamwork (karja sama tim)

Karena keputusan dalam proses berdasarkan konsensus dan melalui diskusi, maka setiap individu memahami posisinya di dalam tim. Hal itu dapat memperkokoh kerja tim.

d. Berorientasi pada dokumentasi

Dokumen mengenai semua data yang berhubungan dengan segala proses dan perbandingan persyaratan pelanggan merupakan hasil dari proses QFD.

Dalam penelitian ini, data diambil dari populasi pelanggan PT.Interyasa Dumai yang berjumlah 120 orang pelanggan. Sampel diambil dengan mengunakan rumus slovin, pengambilan sampel dilakukan menggunakan Teknik Sampling insidental. Sampling insidental adalah pengambilan sampel dengan secara kebetulan, siapa saja yang kebetulan bertemu saat mengambil sampel.

$$
n=\frac{\mathrm{N}}{1+\mathrm{Ne}^{2}}
$$

Dimana :

$\mathrm{n} \quad=$ Ukuran sampel

$\mathrm{N} \quad=$ Ukuran populasi

$\mathrm{e}^{2} \quad=$ Tingkat ketelitian

Dari keterangan diatas dapat dihitung sampel minimal untuk penelitian ini adalah 55 Sampel. 


\section{Hasil dan Pembahasan}

\section{Perhitungan Nilai GAP}

Nilai Servqual setiap dimensi kualitas akan diperinci dalam variabel pendukungnya.

\begin{tabular}{|c|c|c|c|c|}
\hline Dimensi Senqual & Variabel & Ekspektasi & Persepsi & Gap \\
\hline \multirow{5}{*}{ Tangible } & Var 1 & 4,71 & 4,42 & $-0,29$ \\
\hline & Var2 & 4,60 & 4,13 & $-0,47$ \\
\hline & Var3 & 4,13 & 4,13 & $\mathrm{O}, \mathrm{OO}$ \\
\hline & Var4 & 4,20 & 4,13 & $-0,07$ \\
\hline & Vars & 4,38 & 4,38 & $\mathrm{O}, \mathrm{OO}$ \\
\hline \multirow{5}{*}{ Reliability } & Var6 & 4,42 & 4,42 & $\mathrm{O}, \mathrm{OO}$ \\
\hline & Var 7 & 4,27 & 4,27 & $\mathrm{O}, \mathrm{OO}$ \\
\hline & Var8 & 4,42 & 4,42 & $\mathrm{O}, \mathrm{OO}$ \\
\hline & Var9 & 4,35 & 4,35 & $\mathrm{O}, \mathrm{OO}$ \\
\hline & Var 10 & 4,27 & 4,27 & $\mathrm{O}, \mathrm{OO}$ \\
\hline \multirow{5}{*}{ Responsiveness } & Var11 & 4,20 & 4,20 & $\mathrm{O}, \mathrm{OO}$ \\
\hline & Var 12 & 4,26 & 4,25 & $-0,01$ \\
\hline & $\operatorname{Var} 13$ & 4,20 & 4,20 & $\mathrm{O}, \mathrm{OO}$ \\
\hline & Var 14 & 4,10 & 4,09 & $-0,01$ \\
\hline & Var15 & 4,20 & 4,20 & 0,00 \\
\hline \multirow{5}{*}{ Assurance } & Var 16 & 4,26 & 4,25 & $-0,01$ \\
\hline & Var 17 & 4,31 & 4,31 & $\mathrm{O}, \mathrm{OO}$ \\
\hline & Var18 & 4,22 & 4,22 & $\mathrm{O}, \mathrm{OO}$ \\
\hline & Var19 & 4,18 & 4,18 & $\mathrm{O}, \mathrm{OO}$ \\
\hline & $\operatorname{Var} 20$ & 4,42 & 4,42 & $\mathrm{O}, \mathrm{OO}$ \\
\hline \multirow{5}{*}{ Empaty } & $\operatorname{Var} 21$ & 4,13 & 4,13 & $\mathrm{O}, \mathrm{OO}$ \\
\hline & $\operatorname{Var} 22$ & 4,42 & 3,78 & $-0,64$ \\
\hline & $\operatorname{Var} 23$ & 4,42 & 4,42 & $\mathrm{O}, \mathrm{OO}$ \\
\hline & Var 24 & 4,26 & 4,11 & $-0,15$ \\
\hline & Var25 & 4,10 & 4.09 & $-0,01$ \\
\hline
\end{tabular}

Sumber: Pengolahan Data 2015

Penyusunan Customer Needs and Benefits didapat dari hasil wawancara dengan pelanggan. Customer Needs and Benefits ini akan menjadi suara konsumen (voice of customer). Data untuk voice of customer diperoleh dengan menyebarkan kuesioner kepada sampel penelitian. Terdapat dua puluh lima suara konsumen yang berbagi pada tujuh variabel, yang merupakan kebutuhan dan keinginan konsumen terhadap PT. Interyasa Dumai. 


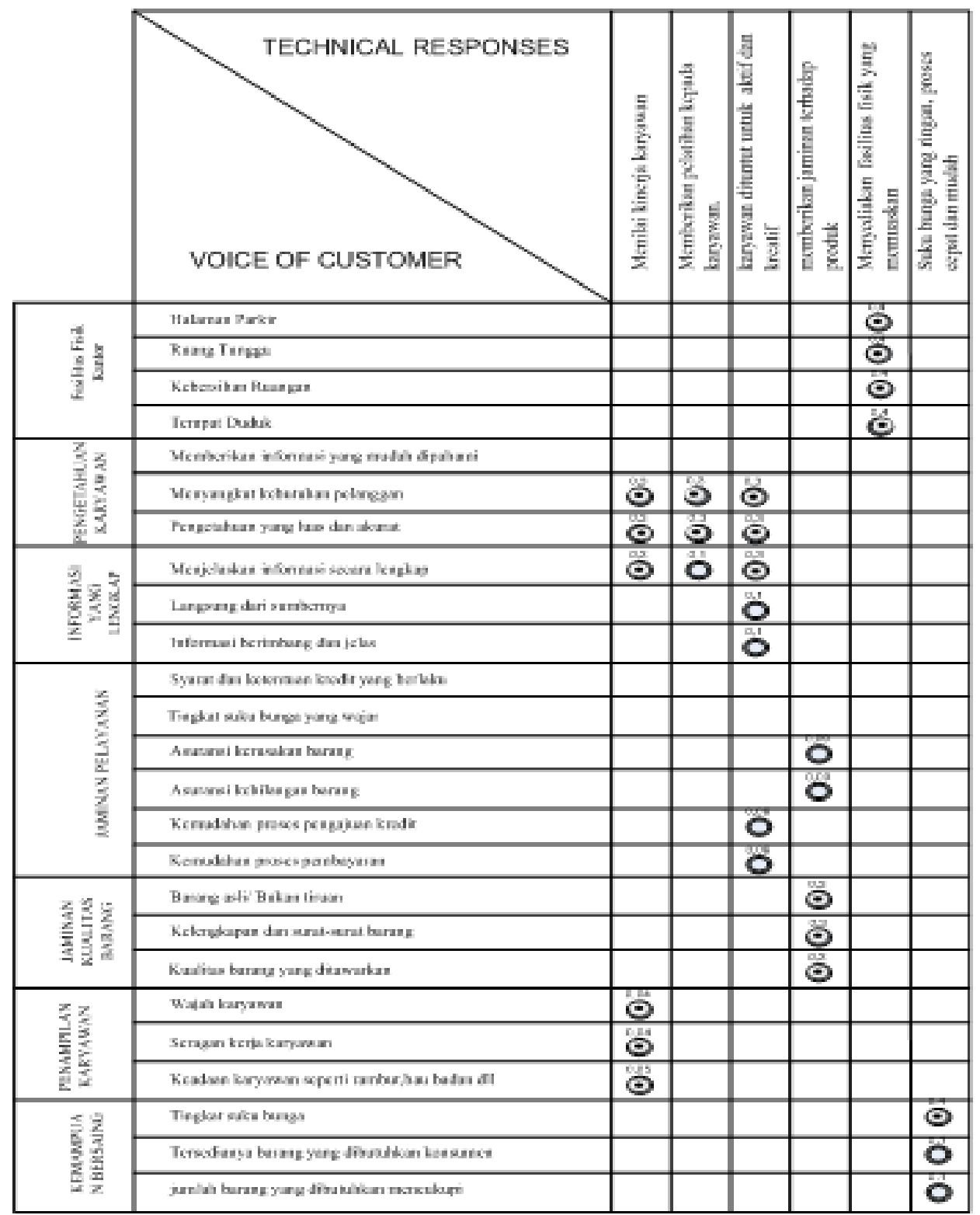

Gambar 4.1 Relationship antara voice of customer dengan technical responses Sumber: Pengolahan data, 2015

Technical Responses merupakan hasil penterjemahan dari keinginan konsumen yang dapat diukur untuk menentukan target yang akan dicapai dan untuk menentukan atribut mana yang nantinya akan dikembangkan. Untuk menentukan parameter mana yang harus dinaikkan atau diturunkan, tentunya kita harus wawancara dan konsultasi dengan pihak manajemen perusahaan, untuk mengetahui Technical Responses yang sesuai dengan keinginan konsumen. Adapun Technical Responses yaitu a) Menilai kinerja karyawan; b) Memberikan pelatihan kepada karyawan; c) Karyawan di tuntut untuk aktif dan kreatif; d) Memberikan jaminan terhadap produk; e) 
Menyediakan fasilitas fisik yang memuaskan; f) Suku bunga yang ringan, proses cepat dan mudah.

Hasil atribut yang menjadi keunggulan PT Interyasa adalah Penampilan atau seragam karyawan dan fasilitas-fasilitas pelayanan yang ada sedangkan atribut menjadi kelemahannya yaitu tempat parkir yang aman, fasilitas fisik layanan, kebersihan lingkungan layanan. Faktor-faktor yang mempengaruhi tingkat kepuasan konsumen PT Interyasa Dumai berdasarkan dimensi quality function deployment yaitu kinerja karyawan, keaktifan dan kekreatifan karyawan, jaminan terhadap produk, fasilitas fisik yang memuaskan, suku bunga yang ringan, proses cepat dan mudah

\section{Simpulan}

Berdasarkan analisis menggunakan metode Servqual didapatkan hasil atribut yang menjadi keunggulan PT Interyasa adalah Penampilan atau seragam karyawan dan fasilitas-fasilitas pelayanan yang ada sedangkan atribut menjadi kelemahannya yaitu tempat parkir yang aman, fasilitas fisik layanan, kebersihan lingkungan layanan. Faktor-faktor yang mempengaruhi tingkat kepuasan konsumen PT Interyasa Dumai berdasarkan dimensi quality function deployment yaitu kinerja karyawan, keaktifan dan kekreatifan karyawan, jaminan terhadap produk, fasilitas fisik yang memuaskan, suku bunga yang ringan, proses cepat dan mudah.

\section{DAFTAR PUSTAKA}

Arian, Dhini dan Puspita, Indi. "Penentuan Prioritas Perbaikan Pelayanan Penumpang Di Terminal 2 Bandara Internasional Soekarno-Hatta Dengan Menggunakan Metode Servqual Dan IPA" Proceeding SNTI dan Kongres BKSTI VI, 2011.

C. Trihendradi, 2008. Step by Step SPSS 16 Analisis dan Statistik, Andi, Yogyakarta.

Lesmana, Andi. Analisis Kepuasan Nasabah Terhadap Pelayanan Bank Mandiri (Persero) Tbk di Bagian Retail \& Consumer Risk Group.

Ridwan, 2003. Skala Pengukuran Variabel-Variabel Penelitian, Alfabeta, Bandung.

Sumadi, Surya, 2005. Metodologi Penelitian. PT. Raja Grafindo Persada, Jakarta.

Tjiptono, Fandy, 2008. Service Manajemen Mewujudkan Layanan Prima, Yogyakarta, Andi Offset.

UNITEK. Vol. 10 No. 2 Juli - Desember 2017 | p-ISSN 2089-3957 | e-ISSN 2580-2585 
Tjiptono, Fandy, 2005. Manajemen Jasa, Andi, Yogyakarta.

Tjiptono, Fandy, 2005. Total Quality Service, Andi, Yogyakarta.

Husein, Umar. 2002. Riset Pemasaran dan Perilaku Konsumen. Jakarta: Gramedia Pustaka Utama.

Wijaya, Tony. 2011. Manajemen Kualitas Jasa, Jakarta, Indeks. 